\title{
An Insight into Cancer and Anticancer Drugs
}

\section{Raichel Nivetha ${ }^{1}$, M Jeslin Jeba Soundari ${ }^{1}$, MSA Muthukumar Nadar ${ }^{1}$, D Premnath ${ }^{1}$, Paulraj Mosae Selvakumar ${ }^{2 *}$ and Ruey-yi Chang ${ }^{3}$}

${ }^{1}$ Department of Biotechnology, Karunya Institute of Technology and Sciences (Deemed to be University), Coimbatore, Tamilnadu, India

${ }^{2}$ Science and Math Program, Asian University for Women, Chittagong, Bangladesh

${ }^{3}$ Department of Life Sciences, National Dong Hwa University, Hualien, Taiwan, China

*Corresponding Author: Paulraj Mosae Selvakumar, Science and Math program, Asian university for women, Chittagong, Bangladesh.

Received: June 03, 2019; Published: July 04, 2019

DOI: $10.31080 /$ ASMS.2019.03.0340

\begin{abstract}
Cancer is one of the most common and widespread diseases in the human population and has been reported to be the second major cause of death globally. The World Health Organisation states that about 200 different types of cancers have been identified worldwide, each of which requires unique approaches for treatment. It also records that 1 in every 6 deaths in the world are due to cancer which clearly evidences for the inevitable necessity for the control and cure of cancer. Unlike normal cells, cancer cells undergo uncontrollable cell division and each division leads to multiple mutations in a continuous fashion. There are various strategies towards targeting cancerous cells. With the advent of conventional therapies, various chemical derivatives are being used as anticancer drugs. This article reviews on the various approaches put forth in the fight against cancer through cancer therapies and drug designing by identifying potent targets. Here we will be discussing about the history of cancer and its advances towards development of anticancer drugs from tip to toe.
\end{abstract}

Keywords: Cancer; Anticancer Drugs; Carcinogen; Cisplatin; QSAR

\section{Introduction}

There are over 200 different types of cancer diseases that have been identified worldwide with 9.6 billion deaths recorded in the year 2018 alone. The annual survey taken by the World cancer research fund in the year 2018 states that over 8,218,216 cases are diagnosed with cancer of which lung cancer tops the table with over 2 million cases [1], followed by breast cancer and colorectal cancer.

As we all know that cells are the basic unit of life, a healthy person's body cells divide continually and replace the dead ones in a controlled manner. The dead cells are replaced by the healthy ones by either shedding away (in case of skin) or getting itself buried inside the bone marrow which is the graveyard of RBCs (erythrocytes) or get carried away along with the excreta. However, it is not
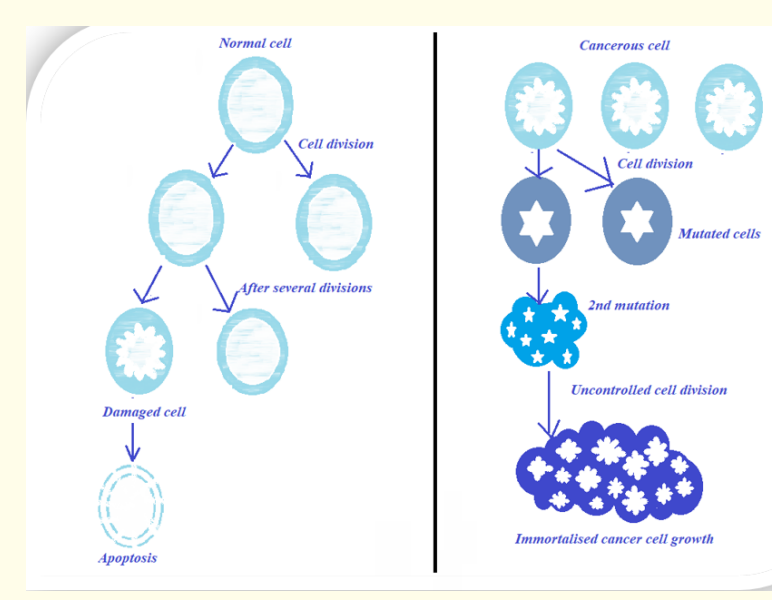

Figure 1: Normal cell division Vs. Cancerous cell division. 
controllably in a continuous fashion (Figure 1). While a normal cell stays in a human on an average of 7 to 10 years, cancerous cells exceeds the count (i.e.)cancer cells are immortal [2]. Moreover, these cells do not die but accumulate in our body causing undesirable and serious health hazards [3].

Cancer cells can develop from any part of the body. Some of the cancer cells show visible growths called tumors. These tumors are a group of cells that show abnormal behaviour and can travel through the blood and lymphatic system by breaking through them and spread to the entire body system. Metastasis is a terminology given to such type of cancer cells that multiply and give rise to new tumors. But, there are other forms of cancers such as leukaemia, which does not develop tumors. As tumors are visible, they can be diagnosed easily when in comparison with non-tumorous cancer cells. It is therefore, the responsibility of each and every individual to diagnose themselves periodically and thereby alleviate the risks in its initial stage itself.

The UK cancer research organisation states that not all cancers are malignant, and that over $50 \%$ of cancer diagnosed patients have lived for more than 5 years. It also states that some cancer patients had survival rate of more than 90\% [4]. One should follow a healthy lifestyle and undergo proper health check up that can help us overcome this dreadful disease. As there are various approaches that are being applied towards combating cancer which works out to be positive, there has been a huge change-over in the mindset of people towards the perspective of cancer which is a healthy sign of getting rid of this disease.

\section{History of cancer}

The word cancer was initially coined by the "Father of Medicine", Hippocrates, as carcinos and carcinoma which describes ulcer causing and non-ulcer causing tumors. Later, it was modified by Celsus, a Roman physician, who termed it as cancer [5]. The chapter of cancer begun as early as in 1600 BC when Edwin Smith papyrus, an Egyptian medical text which dates to the $16^{\text {th }}$ and the $17^{\text {th }}$ dynasties of the Second Intermediate Period in ancient Egypt. This papyrus contained speculations that witnessed cancer to be a deadly serious disease associated to 'the curse of the Gods' [6].

It was also at this period wherein several theories were put forth in the view point of cancer. Firstly, the Humoral theory proposed by Hippocrates believed that the body had 4 humoral bodily fluids namely blood, phlegm, yellow bile, and black bile. When these humors were balanced, a person was healthy. However, imbalance in any of these humors may cause disease. This theory was pioneered by the Romans and remained standard throughout the middle ages for over 1,300 years. During this period, the study of the body, including autopsies, was banned for religious reasons, which limited the progress of medical knowledge [6]. This theory was then followed by the Lymph theory which arose in the year 1540 as a result of the failure of Andreas Vesalius to confirm the existence of black bile of the humoral theory [7] .The lymph theory proposed that cancer was developed by one of the fluid that runs through our body called lymph. This theory was supported in 17 th century by Stahl and Hoffman who hypothesized that cancer was composed of lymph, a fluid in our body that is constantly thrown out by the blood [8]. John Hunter, the Scottish surgeon from the 1700 s, agreed that tumors grow from lymph constantly released from blood [23]. Lusitani and Tulp revealed the contagion theory in 1649 and 1652, respectively. They proposed that cancer patients should be secluded outside cities and towns, in order to prevent the spread of cancer [6]. The blastema theory that emerged in 1838 demonstrated that cancer is not made by lymph but by cells. This theory was proposed by a German pathologist Johannes Muller, and he believed that cancer cells did not come from normal cells. Muller continued that cancer cells developed from budding elements (blastema). His student, Rudolph Virchow, concluded that all cells, including cancer cells, are derived from other cells. The chronic irritation theory proposed by Virchow stated that chronic irritation was the root of cancer, but he believed that cancers "spread like a liquid" [6]. But In the 1860s, German surgeon, Karl Thiersch, disproved the theory by stating that cancers metastasize through the spread of malignant cells and not through some unidentified fluid. Regardless of the advances in the understanding of cancer, from the late 1800s till the 1920s, trauma was believed to cause cancer. The first insight towards the cause of human cancer happened in the 18th century when John Hill found that the reason behind nasal polyps was due to the use of snuffs.

Similarly Percival Pott and Bernardin Ramazzini figured out that soot from Chimney and certain reproductive factors are associated behind the cause of scrotal and breast cancer respectively [1]. This belief was maintained in spite of the failure of injury to cause cancer in experimental animals. The infectious disease theory was proposed by Zacutus and Nicholas, the doctors in Holland. These doctors believed that cancer was contagious. They made this conclusion based on their experiences with breast cancer in members of the same family circle. 


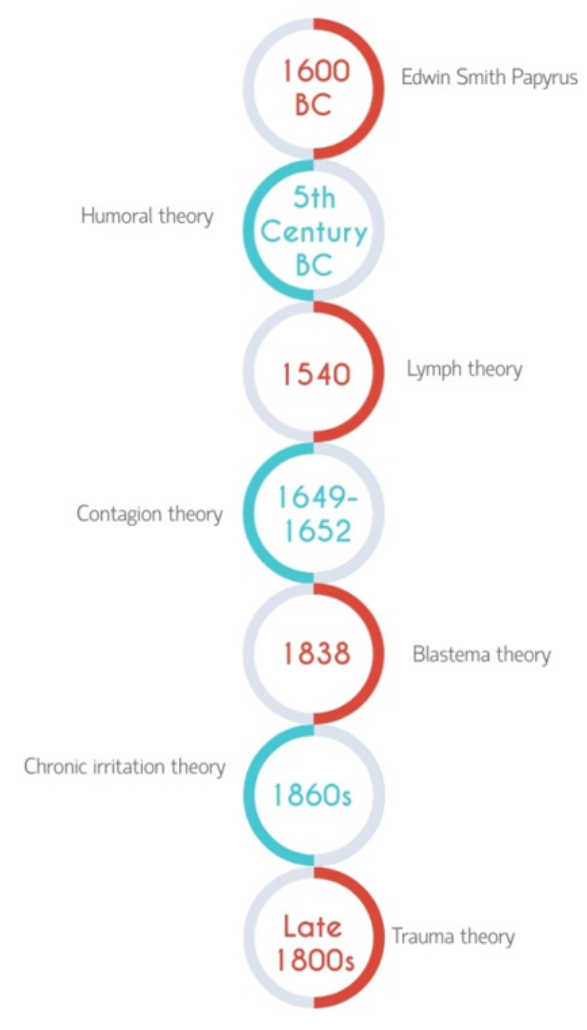

Figure 2: Timeline on various cancer theories of the past [5].

The $17^{\text {th }}$ and $18^{\text {th }}$ centuries were the time when people believed that cancer was contagious although it's not so. We now know that certain viruses, bacteria, and parasites can augment a person's risk of developing cancer [6].

\section{Rationales for cancer progression}

Cancer progression may be due to diverse reasons. Its development and progression are sometimes joined to a series of changes within the activity of cell cycle regulators. The various reasons for the development and progression of cancer are discussed below.

One reason may be due to loss of contact inhibition in cancer cells that reflect the loss of a mechanism that normally maintains tissue balance in our body [10]. Contact inhibition is a regulatory mechanism that functions to keep cells growing into a substrate. If the cell occupies the entire substrate, the normal cells will stop replicating. As motile cells come into contact in confluent ones, they exhibit decreased mobility and mitosis [11]. However in case of cancerous cells, instead of following this property, they replicate uncontrollably thereby promoting cancer progression.

Another characteristic of cancer cells is their replicative immortality, a term for describing uncontrollable cell division. They can divide multiple times than a normal cell of the body [12]. In general, human cells proliferate by a concept known as "The Hayflick's limit". The Hayflick Limit is a concept that explains the mechanisms behind cellular aging. The conception states that a traditional human cell will solely replicate and divide forty to sixty times before it cannot divide any more, and at last, these cells grow old and eventually break down by programmed cell death or apoptosis [13]. Cancer cells however resist contact inhibition by growing uncontrollably and this is termed as "replicative immortality".

Cancer cells will divide for the most part by expressing a link protein such as an enzyme, which reverses the wearing down of chromosome ends that normally happens during each cell division [14]. A telomere is a region of repetitive sequences at each end of eukaryotic chromosomes in most of the eukaryotes that protect the end of the chromosome from DNA damage or fusion with neighboring chromosomes [15]. Telomerase is the enzyme responsible for maintaining telomere length by the addition of guanine-rich sequence repeats. In most tumor cells, the replication potential is unlimited. The role of maintaining telomere length is poorly studied because of the inability of DNA polymerase to completely copy DNA at the ends of chromosomes; therefore, approximately 50 nucleotides are lost during each cell cycle, which results in gradual telomere length shortening [16].

An error in DNA repair may attach a proto-oncogene to part of a different gene, producing a "combo" protein with unregulated activity [17]. Activated oncogenes cause apoptotic cells to survive and proliferate instead [3]. Genes that ordinarily block cell cycle progression are referred to as tumor suppressors. Tumor suppressors stop the formation of cancerous tumors once they are operating properly, and tumors may form when they mutate so they no longer work. One of the foremost vital growth suppressors is growth macromolecule p53, that plays a key role within the cellular response to deoxyribonucleic acid harm. p53 acts primarily at the G1 checkpoint (controlling the G_11), where it blocks cell cycle progression in response to damaged DNA and other unfavorable conditions [11]. 


\section{Types of cancer}

The American Cancer Society 2019 survey stated that the estimated annual incidence for 2019 had to be 40,000 cases or more. The most widespread type of cancer on the list is breast cancer, with 271,270 new cases expected in the United States in 2019. The next most typical cancers are carcinoma and prostatic adenocarcinoma. For 2019, the calculable variety of latest cases of carcinoma and body part cancer are 1,01, 420 and 44,180, respectively, adding to a total of 145,600 new cases of colorectal cancer [16].

\begin{tabular}{|l|c|c|}
\hline Type of cancer & Expected Cases & Expected deaths \\
\hline Bladder & 80,470 & 17,670 \\
\hline $\begin{array}{l}\text { Breast (Female - } \\
\text { Male) }\end{array}$ & $268,600-2,670$ & $41,760-500$ \\
\hline $\begin{array}{l}\text { Colon and Rectal } \\
\text { (Combined) }\end{array}$ & 145,600 & 51,020 \\
\hline Endometrial & 61,880 & 12,160 \\
\hline Renal & 73,820 & 14,770 \\
\hline Leukemia (All Types) & 61,780 & 22,840 \\
\hline $\begin{array}{l}\text { Liver and Intrahepatic } \\
\text { Bile Duct }\end{array}$ & 42,030 & 31,780 \\
\hline $\begin{array}{l}\text { Lung (Including } \\
\text { Bronchus) }\end{array}$ & 228,150 & 142,670 \\
\hline Melanoma & 96,480 & 7,230 \\
\hline $\begin{array}{l}\text { Non-Hodgkin } \\
\text { Lymphoma }\end{array}$ & 74,200 & 19,970 \\
\hline Pancreatic & 56,770 & 45,750 \\
\hline Prostate & 174,650 & 31,620 \\
\hline Thyroid & 52,070 & 2,170 \\
\hline
\end{tabular}

Table 1: Table showing most common types of cancer recorded in the year 2019.

Courtesy: American Cancer Society: Cancer Facts and Figures 2019. Atlanta, Ga: American Cancer Society, 2019 [1].

The major types of cancer are carcinoma, sarcoma, melanoma, lymphoma, and leukemia of which carcinomas are the most commonly diagnosed cancers that originate from the skin, lungs, breasts, pancreas, and other organs and glands. Lymphomas are cancers that arise from lymphocytes. Leukemia is a term used for blood cancer that doesn't usually form solid tumors. Melanomas are skin cancers and sarcomas are relatively uncommon tumors that arise in bone, muscle, fat, blood vessels, cartilage, or other soft or connective tissues of the body [20].
For a cell to divide into 2 daughter cells, it has to follow a series of cyclic processes commencing from G0 phase and followed by $\mathrm{G} 1 \rightarrow \mathrm{S} \rightarrow \mathrm{G} 2 \rightarrow \mathrm{M}$, which is commonly known as the cell cycle wherein cyclins and CDKs play a major role in triggering each phase. In order to ensure the correctness of the cell cycle process, there are check points at G1, G2 and M phases respectively [21]. As far as the CDKs and cyclins are in a limited amount, the progression of cells is limited too. But if there is any kind of increase in the concentration of these enzymes, the progression augments. The mechanism of cancer is mainly due to genetic mutation which alters the enzyme concentration [22]. This increase may be due to four main factors namely point mutation, DNA amplification, chromosomal rearrangement and epigenetic modifications such as methylation or acetylation [23]. Uncontrolled cell growth is caused by the activation of oncogenes such as RAS gene and MYC gene or by the inactivation of tumor suppressor genes such as p53, APC, BRCA 1/2, and these oncogenes are the reason why the cancer cells bypass these three checkpoints too [24].

WHO states that the first critical step in the management of cancer is to establish the diagnosis based on pathological examination. Obtaining a tumor sample is achieved through performing a biopsy or aspiration that may require an intervention such as an image-guided procedure or endoscopy [1]. However the common approaches towards cancer diagnosis involve physical examination, lab tests, imaging tests and biopsy [25]. During physical examination, the examiner may look for abnormalities, changes in skin color, organ enlargement; lab tests involve urine and blood tests to check for blood cell count; imaging tests embody CT (Computed Tomography) scan, bone scan, Magnetic resonance imaging (MRI), antilepton emission picturing (PET) scan, ultrasound and X-ray, biopsy where cell samples are collected for testing below the microscope to, observe cell morphology [26].

\section{Carcinogens}

A carcinogen is any substance that can increase the incidence of neoplasm when compared with the occurrence in suitable controls in a defined test organism (Comprehensive Toxicology, 2010). According to the International Agency for Research on Cancer (IARC), a carcinogen is defined as a driving force that increases the risk of cancer [27]. It is believed that chemicals constitute the most diverse group of carcinogens [28]. IARC classifies chemicals on their basis of their carcinogenicity into four main groups (Figure 3). 


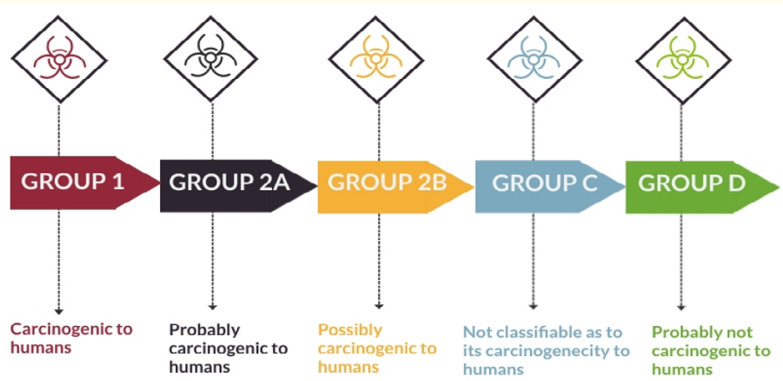

Figure 3: The four groups of carcinogens classified under IARC.

Up to 4,000 chemicals have been identified in tobacco smoke thus far of which more than 70 chemicals are known to cause, initiate or promote cancer $[29,30]$. As we all know that tobacco is a potent carcinogen, it is classified under Group 1 carcinogen [40]. A carcinogen is termed genotoxic if it binds to the cytoplasmic DNA which may cause genetic alterations due to DNA mutation [28]. Most of the carcinogens enter as inactive compounds as has to be activated by enzymes [32]. Not all carcinogens require metabolic activation in order to induce cancer. These directly acting carcinogens are carcinogenic at multiple sites which include agents such as epoxides, mustard gases so on and so forth [33].

\begin{tabular}{|l|l|} 
Food \\
preservatives
\end{tabular}

Table 2: Some of the common carcinogens used in different industries (Courtesy: PubChem).
Anticancer drugs and their mechanism

An anticancer drug is a molecule that is effective in the treatment of malignant or cancerous disease. There are many major categories of antineoplastic drugs that hold alkylating agents, antimetabolites, natural products, and hormones and drugs that demonstrate anticancer activity and used in the treatment of malignant disease. The term chemotherapy is frequently related to the use of anticancer drugs, though it more accurately refers to the use of chemical compounds that treat disease generally [34].

The early period of the twentieth century was the time when chemotherapy came in to picture. The famous German chemist Paul Ehrlich who pioneered drug development coined the term "chemotherapy" to treat infectious diseases by the use of chemicals and was the first person to put forth the effectiveness of animal models to display a series of chemicals for their activity against diseases that had a major implication on cancer drug development [35]. In 1908, he used rabbit model for treating syphilis that led development of arsenicals to treat this disease. He also worked on treating cancer additionally; however, it wasn't that successful [35]. The period of cancer chemotherapy thus arose in the 1940s with the first use of nitrogen mustards and folic acid antagonist drugs [36] that served as a model for various alkylating agents and killed rapidly growing cancer cells by damaging their DNA [6]. The targeted therapy revolutions consequently embarked thereafter, but many of the early traditional principles are still being followed [36].

Abruptly after the discovery of nitrogen mustard, Sidney Farber, a pathologist from Boston identified that aminopterin, a folic acid similar vitamin was fundamental for DNA metabolism [37]. Aminopterin and amethopterin (also known as methotrexate) are the analogues that blocked a critical chemical reaction needed for DNA replication. The research concluded that antifolates could suppress proliferation of malignant cells, and re-establish normal bone-marrow function. In 1947, Babe Ruth [38], a Nasopharynx cancer victim, became one of the first human subjects of teropterin (an aminopterin analogue) administration. Dr. Richard Lewisohn of New York treated the patient with that drug, and after several months, Ruth's condition improved. However, she died the following year [25]. The National Cancer Institute in 1956 discovered that methotrexate alone could cure choriocarcinoma, a germ-cell malignancy originating in placental trophoblastic cells [39]. Since then, other researchers discovered drugs that block different functions in cell growth and replication and the era of chemotherapy started so.

The theory of using adjuvant therapies to supplement primary surgery evolved in the middle of the $20^{\text {th }}$ century where Gianni 
Bonadonna and his colleagues from the Instituto Tumori in Italy in 1973, conducted a trial that demonstrated more constructive survival outcomes which added on to use of Cyclophosphamide Methotrexate Fluorouracil (CMF) after the initial mastectomy.

Adjuvant systemic therapy and radiotherapy are often given following surgery for many types of cancer, including colon cancer, lung cancer, pancreatic cancer, breast cancer, prostate cancer, and some gynecological cancers. Some sorts of cancer fail to profit from adjuvant medical care, however. Such cancers include urinary organ cell cancer, and certain forms of brain cancer. Radiotherapy or systemic therapy such as chemotherapy, immunotherapy or biological response modifiers or hormone therapy are the commonly given adjuvant therapy before cancer surgery.

The use of combination therapy to treat cancer was initiated within the 60 s by treating infectious disease employing a combination of antibiotics to cut back the chance of resistance. The therapy worked for the treatment of cancer as well. Using this approach, cancers that had previously been almost universally fatal such as acute lymphocytic leukemia and Hodgkin's lymphoma became curable. Since then, combination chemotherapy has been accepted to be the treatment of many other cancers as well [40]. Combination therapy gained momentum in cancer studies and more advantageous than sequential therapy in the recent years, with various studies demonstrating higher response rates with combinations of drugs compared to mono therapies, and the FDA recently approving therapeutic combination drugs that confirmed superior safety and efficacy to mono therapies [39].

Oncology clinical trials proved to be the cornerstone for improving outcomes for individuals at danger living with cancer [40]. A clinical trial is a type of patient-based clinical research study which potentially allocates a participant, known as a human subject, to one or more biomedical or behavioral interventions to examine health-related outcomes [41]. Cancer patients take part in clinical trials to promote experimental treatments themselves, and to aid scientists comprehend their diseases to develop treatments for other patients. The participation confronts include access issues like inclusion and exclusion criteria or country of residence, and an often underestimated impact on a psychosocial, financial and physical stage [42].

The activities of various anticancer drugs and their target sites are mentioned in figure 4 , and a brief description of certain commercially important drugs are mentioned in table 2 respectively.

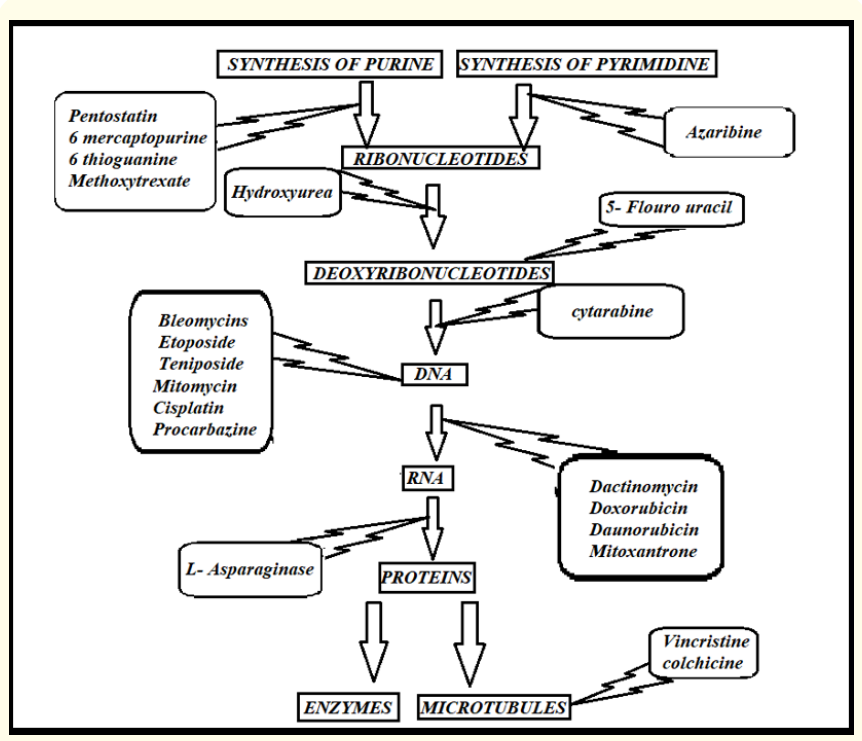

Figure 4: Schematic representation of common anticancer drugs and their target site [43].

\section{Recent drug delivery process}

Recently, several therapeutic approaches have been developed to target the immune cells and inflammatory cytokines. The prime aim of all these strategies is to enhance the response of the immune system towards inflammation and cancer [44]. Variety of nanoscale compounds based on synthetic polymers, proteins, lipids, and organic and inorganic particles have been employed for the advancement of cancer therapeutics [45]. Zero dimensional (0-D) fluorescent nanoparticles, such as quantum dots (QDs), have been materialized to be one of the most promising nanoparticles for targeted and traceable drug delivery systems [46]. Advances in the field of nanomedicine include "smart" drug delivery includes multiple levels of targeting and extended-release drug-delivery systems that provide further techniques of overcoming limitations associated with traditional cancer therapy. In recent times, the idea of merging smart drug delivery with extended-release has paved way in developing highly efficient nanoparticles with improved delivery, bioavailability, and safety profiles [47].

\section{QSAR studies}

Quantitative structure-activity relationship (QSAR) studies are essential to be understood when a protein is the target and there is a need to find a suitable molecule, which can curb the activity of target. QSAR existed even before computers became popular, nevertheless, with the ease of computers and databases QSAR acts as 


\begin{tabular}{|c|c|c|c|c|}
\hline S. No & Name of the drug & Nature & Other names & Structure and property \\
\hline 1. & Aminopterin & antineoplastic & $\begin{array}{c}\text { Aminopteridine, } \\
\text { Aminopterine, APGA, } \\
\text { Minopterin }\end{array}$ & An Enzyme inhibitor that binds with dihydrofolate reduc- \\
\hline 2. & $\begin{array}{l}\text { Methotrexate (or) } \\
\text { amethopterin }\end{array}$ & $\begin{array}{c}\text { Anti-metabolite } \\
\text { and anti-neoplastic }\end{array}$ & $\begin{array}{l}\text { methotrexate, } \\
\text { MTX, Rheumatrex, } \\
\text { and Trexall. }\end{array}$ & $\begin{array}{l}\text { Inhibits tetrahydrofolate dehydrogenase essential for thy- } \\
\text { midylate synthesis. }\end{array}$ \\
\hline 3. & Thalidomide & & $\begin{array}{l}\text { Contergan, Thalo- } \\
\text { mid, Immunoprin, } \\
\text { Talidex, Talizer, Neu- } \\
\text { rosedyn, Distaval }\end{array}$ & $\begin{array}{l}\text { Used in the treatment of multiple myeloma and complica- } \\
\text { tion of leprosy. }\end{array}$ \\
\hline 4. & Mechlorethamine & Alkalyting agent & $\begin{array}{l}\text { Chlormethine } \\
\text { Nitrogen mustard } \\
\text { Chlorethazine } \\
\text { Mustine }\end{array}$ & $\begin{array}{l}\text { An alkylating agent that forms DNA adducts and cross- } \\
\text { links, to inhibit quickly proliferating cells. }\end{array}$ \\
\hline 5. & Actinomycin D & Antibiotic & $\begin{array}{l}\text { Dactinomycin, } \\
\text { cosmegan }\end{array}$ & Inhibits transcription. and averts elongation of RNA chain \\
\hline
\end{tabular}




\begin{tabular}{|c|c|c|c|c|}
\hline 6. & Cisplatin & $\begin{array}{l}\text { Platinum-based } \\
\text { antineoplastic }\end{array}$ & $\begin{array}{c}\text { Cisplatinum, } \\
\text { platamin, neoplatin, } \\
\text { cismaplat }\end{array}$ & $\begin{array}{l}\text { Interferes with DNA replication, and destroying proliferat- } \\
\text { ing cells. }\end{array}$ \\
\hline 7. & Vincristine & Alkaloid & $\begin{array}{l}\text { Leurocristine, } \\
\text { Vincasar, oncovin }\end{array}$ & $\begin{array}{l}\text { Ceases the tubulin dimers from polymerizing, and causes } \\
\text { apoptosis. }\end{array}$ \\
\hline 8. & Doxorubicin & $\begin{array}{l}\text { a } \mathrm{n} \mathrm{th} \mathrm{r} \text { a c y - } \\
\text { cline and antitumor } \\
\text { antibiotic }\end{array}$ & $\begin{array}{l}\text { Adriamycin, Caelyx, } \\
\text { Myocet }\end{array}$ & $\begin{array}{l}\text { Intercalates and inhibits macromolecular biosynthesis caus- } \\
\text { ing DNA damage. }\end{array}$ \\
\hline 9. & Mercaptopurine & Purine analogue & Purinethol & $\begin{array}{l}\text { Inhibits purine synthesis and metabolism by altering the } \\
\text { synthesis and function of nucleic acids. }\end{array}$ \\
\hline
\end{tabular}

Table 3: A list of well known commercially available anticancer drugs (Courtesy: PubChem)

an essential component of drug discovery these days [48a,b]. The QSAR studies on antitumor drugs like nitrosoureas, aniline mustards, and aryl triazenes concluded that present drugs in clinical use are more hydrophilic than one might expect [49]. The activity transforming the effect of the structural features may serve to illustrate groundwork of novel anticancer drug hypothesis entrants, and also to provide a better understanding towards mechanisms of action of drugs [50]. The rational identification of new lead drugs and activity optimization via QSAR studies saves the cost of product development as predictions inturn could reduce the need for expensive animal tests, thus promoting a greener chemistry [51]. Some of the atomic physiochemical properties such as Distance atomic physicochemical parameter energy relationships (DAPPER), can be better understood by novel structure-activity relationship such as 3D QSAR method using molecular descriptors, is validated on standard datasets [52]. 
Other novel approaches towards cancer treatment

Cancer treatment has advanced rapidly over the last 70 years starting from cytotoxic agents against cancer tumors. However, significant systemic side effects towards targeted therapies which trigger cancer-cell cause apoptosis towards cancer cells but healthy tissues remain intact [53].

Recent evidences state that electron transfer (ET), reactive oxygen species (ROS) and oxidative stress (OS) plays an important role in the mechanism of many anticancer drugs [54]. It has been found that most chemotherapeutics increase intracellular levels of reactive oxygen species (ROS), and alter the redox-homeostasis of cancerous cells. This is due to the induction of oxidative stress and ROS-mediated cell damage in cancer [55]. The regular ET functionalities that square measure typically there within the drug metabolites square measure quinones (or precursors), metal complexes (or complexors), hydroxylamine and nitroso from ArNO2 or ArNH2, and conjugated imines (or iminium species). These ET agents work catalytically in redox cycling with the development of ROS from oxygen which is then confirmed by the use of electrochemical data. The generated metabolites generally hold reduction potentials acquiescent to ET in vivo, thus giving rise to ROS. The resulting OS destroys the cancer cell in reply. The action has been termed phagomimetic based on correspondence to phagocytosis. It is important to make out that drug action is mostly multipronged [54].

Increasing repetition of class tumors and side-effects of therapy agents cut back the clinical effectiveness of an outsized kind of antineoplastic agents that square measure presently getting used. Thus, there is constant need to develop alternative or synergistic anticancer drugs with minimal side-effects. One such strategy to develop effective anticancer agents is to research anticancer agents derived from natural sources such as plants and their derivatives. Vinca alkaloid and their derivatives have been used extensively for the treatment of various types of cancers. Polyphenols form one of the most important and widely used classes of plant-derived therapeutics for cancer prevention or chemotherapy because of their antineoplastic properties [44].

Thomas., et al, reported that the new class of drugs was the first to target KAT6A and KAT6B proteins behave as a new weapon for fighting cancer that are known to play an important role in driving cancer [54]. Unlike chemotherapy and radiotherapy that work by causing irreversible DNA damage, this new class of compounds stops cancer progression by causing cell senescence thereby switching off their ability to 'trigger' cell cycle initiation.

Immunotherapeutic approaches using immune cells or targeting immune cells involved in cancer and inflammation offer novel approaches to treat these changes. These cytokines also adapt responses of the immune cells involved in inflammation and tumor surveillance [44].

There might be some group of people who might feel that natural way of treating cancer is novel and successful nowadays. But it is not so. Alternative treatments such as acupuncture, yoga, meditation may play important roles in cancer care. These techniques may improve cancer-related fatigue, pain, mental health, and quality of life when they are added to standard cancer therapy [57]. Some doctors reject alternative medicine completely to avoid unfortunate cases. A study taken on the month of august recorded in the Journal of the National Cancer Institute looked at 281 cases with non-metastatic breast, lung, colorectal, and prostate cancers who chose to be treated solely with an alternative approach, and compared their survival with patients who received conventional cancer treatment. And the result stated that overall; those in the alternative medicine group were 2.5 times more likely to die [58].

The national cancer institute states that the overall cancer death rate has declined to over $26 \%$ since the early 1990s [58]. Though cancer has reduced multifold, there are still new cases appearing with new symptoms of cancer. The study continues that the number of new cancer cases per year is expected to rise to 23.6 million by 2030 [58] which clearly demonstrate the ardent need for the development of novel anticancer agents with specific biomarkers as molecular targets.

\section{Market survey on anticancer drugs}

A market survey taken Global anticancer drugs by transparency market research states that anticancer drugs at a global level was valued at US\$ 85.0 Bn in the year 2016 and is projected to expand at a Compound Annual Growth Rate (CAGR) of about 6 to $7 \%$ from 2017 to 2025 to reach US\$ $155.6 \mathrm{Bn}$ in 2025 thereby offering a scrupulous perceptive of anticancer drugs market across the globe its key trends, drivers, restraints, and opportunities [65].

Worldwide, the global anticancer drugs market is segmented in to North America, Europe, Asia Pacific, Latin America and Middle East and Africa of which North America region contributed the most. The global anticancer drugs market of North America is projected to expand at CAGR of over $6 \%$ and European antican- 
cer drugs market, to an estimated growth rate of $6.7 \%$ over forecast period from 2017 to 2025 respectively. Markets such as India, China, and Brazil are still emerging and markets such as Japan and Australia are well established [66].

Targeted drugs hold over $40 \%$ of the global anticancer drugs market. Minimum side effects as compared to cytotoxic drugs, high specificity of the drugs, and effective results of these drugs is expected to drive the growth of the market sector through 2025 [67]. Some of the high-flying companies competing in the anticancer drugs markets include F. Hoffmann-La Roche Ltd, Eli Lilly and Company, Celgene Corporation, Novartis AG, Pfizer Inc, Amgen Inc, Bayer AG, AstraZeneca, Takeda Pharmaceutical Company Limited, Merck and Co., Inc. etc. [66,67].

\section{Literature survey on anticancer drugs}

34609 documents are obtained from the Scopus search engine for the keyword "Anticancer Drugs" from the year 1953 to 2019 of which 27,000 documents are of article type. When the subject area is concerned, Biochemistry, Genetics, Molecular Biology and chemistry are the most dealt division (Figure 5) with nearly 7409 documents followed by medicine(6852 documents) and pharmacology(5502 documents). USA is the most contributing country as per the results analysed in Scopus [68]. Further analyses state that the Chinese Academy of Sciences contributed most of the documents (nearly 746 documents) between the above mentioned timespan. There has been a tremendous hike in the number of documents published between the year 2007 till date from a count of 1000 to 2500 respectively. Thus these data clearly evidences the contribution of researchers towards cancer and related studies.

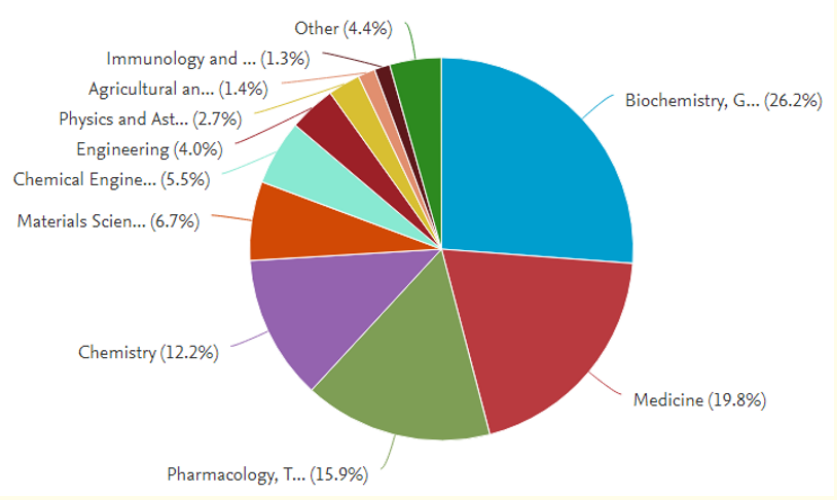

Figure 5: Results obtained from the Scopus analyser for the keyword "Anticancer Drugs" (Documents by subject type) from the year 1953 to 2019 [Courtesy: www.scopus.com].

\section{Conclusion}

The causes for cancer progression are still a maze of unrevealed mysteries. The appropriate role of the immune system in both inflammation and cancer is not yet absolutely established. Furthermore, cytokines released by different cells in response to cancer and inflammation exerts surplus of effects on inflammation and the cancer prognosis. There is much advancement towards cancer treatment in the recent past. However, the causes of many cancers are not fully understood, making it difficult to develop effective treatments, reflected in the high failure rate of cancer drugs during clinical development. Although modified and comprehensiverelease drug-delivery systems have been studied broadly, there remain gaps in the literature regarding their usage in cancer treatment.

Though there many advances in the treatment of most cancers by current drug delivery systems, much work lies ahead in scrutinizing the death rates owing to cancer. Therefore, with the understandings analysed from the recent researches on advancements of anticancer drugs and remembering the traditional techniques as well, one can identify new targets and thus design novel anticancer drugs to bridge the gap of drawbacks that are discussed above.

\section{Bibliography}

1. World cancer research fund, https://www.wcrf.org/dietandcancer/cancer-trends/data-cancer-frequency-country.

2. Maarten J Wensink. "Size longevity and cancer: age structure". Proceedings. Biological sciences 283.1838 (2016): 20161510.

3. Cancer Risk Factors, MedicineNet, https://www.medicinenet. com/cancer_causes/article.htm\#cancer_risk_factor_facts.

4. World Health Organisation, https://www.who.int/newsroom/fact-sheets/detail/cancer.

5. Diamandopoulos GT. "Cancer: an historical perspective". Anticancer Research 16.4A (1996): 1595-1602.

6. American Cancer Society, https://www.cancer.org/cancer/ cancer-basics/history-of-cancer/what-is-cancer.html.

7. Amil Shah. "Solving the Riddle of Cancer: New Genetic Approaches to Treatment (1994): 5-7.

8. Transparency Market Research, https://www.transparencymarketresearch.com/anticancer-drugs-market.html 
9. Weisse Allen B. "Medical Odysseys: The Different and Sometimes Unexpected Pathways to Twentieth-Century Medical Discoveries". Rutgers University Press. p. 127. ISBN 978-08135- (1991):1616-1615.

10. Hanahan D and Weinberg R A. "Hallmarks of cancer: the next generation”. Cell 144.5 (2011): 646-674.

11. Wieser RJ and Oesch F. "Contact Inhibition of Growth of Human Diploid Fibroblasts by Immobilized Plasma Membrane Glycoproteins". Journal of Cell Biology 103.2 (1986): 361367.

12. Bartlett Zane. "The Hayflick Limit". Embryo Project Encyclopedia ISSN: 1940-5030 http://embryo.asu.edu/handle/10776/8237. (2014).

13. Seluanov Andrei., et al. "Hypersensitivity to contact inhibition provides a clue to cancer resistance of naked molerat". Proceedings of the National Academy of Sciences 106.46 (2009): 19352-19357.

14. The Biology of Cancer, http://sphweb.bumc.bu.edu/otlt/ MPH-Modules/PH/PH709_Cancer/

15. Cano MI., et al. "Telomerase in kinetoplastid parasitic protozoa". Proceedings of the National Academy of Sciences of the United States of America 96.7 (1999): 3616-3621.

16. American Cancer Society: Cancer Facts and Figures Atlanta, Ga: American Cancer Society (2019).

17. Lodish H., et al. "Proto-oncogenes and tumor suppressor genes". Molecular cell biology, 4th ed., section 24.2 (2000).

18. Raven P H., et al. "Cancer is a failure of cell cycle control in biology 10th ed"., AP ed (2014): 202-204.

19. American Cancer Society: Cancer Facts and Figures Atlanta, Ga: American Cancer Society, (2019).

20. WebMD, https://www.webmd.com/cancer/understandingcancer-basics

21. Cooper GM. "The cell: a molecular approach". Washington, DC: ASM Press (1997).

22. D Duan. Pharmacology 601, Sec VII: Chemotherapy (lecture notes), Department of Pharmacology, University of Nevada 61 (2004).

23. ASCO Journals, https://www.cancer.net/navigating-cancer-care/cancer-basics/genetics/genetics-cancer ( March 2018).

24. Taylor WR and Stark GR. "Regulation of the G2/M transition by p53". Oncogene 20.15 (2001): 1803-1815.

25. The Biology of Cancer, http://sphweb.bumc.bu.edu/otlt/ MPH-Modules/PH/PH709_Cancer/

26. Stat news, https://www.statnews.com/2017/08/29/cancertreatment-alternative-medicine/

27. World Health Organization. International Agency for Research on Cancer, IARC, Monographs on the Evaluation of Carcinogenic Risks to Humans, Tobacco Smoke and Involuntary Smoking 831187 (2002).

28. Thomas C King and Neoplasia. "Elsevier's Integrated Pathology". (2007).

29. Stephen S Hecht. "Research Opportunities Related to Establishing Standards for Tobacco Products under the Family Smoking Prevention and Tobacco Control Act, Nicotine Tobacco Research, first published online (2011).

30. Adeel Malik., et al. "Databases and QSAR for Cancer Research". Cancer Inform 2 (2006): 99-111.

31. A Report of the Surgeon General, How Tobacco Smoke Causes Disease: What it Means to You, page 5 (2010).

32. Matthew Wallig., et al. "Manifestations of toxic cell injury". Fundamentals of Toxicologic Pathology 2nd ed., (2010)

33. IARC, http://monographs.iarc.fr/

34. Janet L Stringer and Irvin S Snyder. Anticancer drug Encyclopaedia Britannica (2018).

35. Vincent T DeVita Jr and Edward Chu. "A History of Cancer Chemotherapy". Cancer Research 68.21 (2008): 8643-8653.

36. Howard Markel. "Home run king Babe Ruth helped pioneer modern cancer treatment". PBS. (2014-08-15) Retrieved (2018).

37. Li MC., et al. "Effect of methotrexate upon choriocarcinoma". Proceedings of the Society for Experimental Biology and Medicine 93.2 (1956): 361-366.

38. Aftimos SF. "Methotrexate/aminopterin syndrome in an adult: a likely case with ectodermal abnormalities". Clinical Dysmorphology 18.1 (2009): 53-55.

39. Bozic I., et al. "Evolutionary dynamics of cancer in response to targeted combination therapy”. eLife 2(2013): e00747.

40. Elizabeth and Cheryl. "Clinical Trials \& the Role of the Oncology Clinical Trials Nurse". Nursing Clinics of North America 52.1 (2017): 133-148. 
41. The role of clinical trials in cancer treatment, www.Anticancerfund.org

42. Jonathan B Baell., et al. "New KAT6 inhibitors induce senescence and arrest cancer growth". Nature 560 (2018): 253257.

43. WebMD, https://www.webmd.com/cancer/understandingcancer-basics

44. Montville Leigh. "The Big Bam: The Life and Times of Babe Ruth". New York: Broadway Books (2006).

45. Bianco A., et al. "Opportunities and challenges of carbonbased nanomaterials for cancer therapy". Expert Opinion on Drug Delivery 5.3 (2008): 331-342.

46. Kalaydina RV., et al. "Recent advances in "smart" delivery systems for extended drug release in cancer therapy". International Journal of Nanomedicine 13 (2018): 4727-4745.

47. Kalaydina RV., et al. "Recent advances in "smart" delivery systems for extended drug release in cancer therapy". International Journal of Nanomedicine 13 (2018): 4727-4745.

48. a)Khalid, QSAR modeling useful in anti-cancer drug discovery: Prediction of V600EBRAF-dependent p-ERK using Monte Carlo Method, j med chem. Toxicol, 2.1 (2017). b)Hansch C., QSAR in cancer chemotherapy, Farmaco Sci. 34(1):89-104 (1979).

49. https://www.mayoclinic.org/diseases-conditions/cancer/ diagnosis-treatment/drc-20370594

50. Adeel Malik. "Databases and QSAR for Cancer Research". Cancer Inform. 2 (2006): 99-111.

51. Puzyn., et al. "Mark Recent Advances in QSAR Studies". Chapter 14 (2010).

52. Sudipta Senapati., et al. "Controlled drug delivery vehicles for cancer treatment and their performance". Signal Transduction and Targeted Therapy 3 (2018): 7.

53. Nalân Utku. "New Approaches to Treat Cancer - What They Can and Cannot Do". Biotechnol Healthc 8.4 (2017): 25-27.

54. Xinglong. "Immunological Approaches Towards Cancer and Inflammation: A Cross Talk". Frontiers in Immunology 9 (2018): 563.

55. Haotian Yang., et al. "The role of cellular reactive oxygen species in cancer chemotherapy". Journal of Experimental and Clinical Cancer Research 37 (2018): 266.
56. Peter Kovacic and Ratnasamy Somanathan. "Recent Developments in the Mechanism of Anticancer Agents Based on Electron Transfer, Reactive Oxygen Species and Oxidative Stress". Anti-Cancer Agents in Medicinal Chemistry 11.7 (2011): 658668.

57. Skyler B Johnson., et al. "Use of Alternative Medicine for Cancer and Its Impact on Survival". Journal of the National Cancer Institute 110.1 (2018): 121-124.

58. Cancer statistics, Understanding Cancer, National Cancer Institute.

59. Tom Connors. "Anticancer Drug Development: The Way Forward". The Oncologist 1.3 (1996):180-181.

60. Transparency Market Research, https://www.transparencymarketresearch.com/checkout.php?rep_id=12458\&ltype=S.

61. Transparency market research, https://www.transparencymarketresearch.com/sample/sample.php?flag=S\&rep_ id $=12458$.

62. Kardinal CG and Yarbro JW. "A conceptual history of cancer". Seminars in Oncology 6.4 (1979): 396-408.

63. Sudhakar A. "History of Cancer, Ancient and Modern Treatment Methods". Journal of Cancer Science and Therapy 1.2 (2009): 1-4.

64. Lynne Eldridge. "Benefits and risks of combining chemotherapy and/or immunotherapy drugs, MD”. verywellhealth.com (2019).

65. Bianco A., et al. "Opportunities and challenges of carbonbased nanomaterials for cancer therapy". Expert Opinion on Drug Delivery 5 (2008): 331-342.

66. Mathew C Casimiro., et al. "Cyclins and Cell Cycle Control in Cancer and Disease". Genes Cancer 3.11-12 (2012): 649-657.

67. Eccles SA., et al. "Critical research gaps and translational priorities for the successful prevention and treatment of breast cancer". Breast Cancer Research 15.5 (2013): R92.

68. Hansch C. "QSAR in cancer chemotherapy". Farmaco Science 34.1 (1979): 89-104.

69. www.scopus.com

\section{Volume 3 Issue 8 August 2019}

(C) All rights are reserved by Paulraj Mosae Selvakumar., et al. 